\title{
Horst Hilger
}

\section{Jahre Zentralkatalog Baden-Württemberg}

Der Zentralkatalog Baden-Württemberg (ZKBW), der zum 01.01.1996 als AuBenstelle Stuttgart in das BSZ integriert wurde, ist am 31.08.2006 fünfzig Jahre alt geworden. Am 31.08.1956 trat der erste Leiter des ZKBW, Hans Cordes, seinen Dienst in Stuttgart an. Damit begann die eigentliche Arbeit des Zentralkatalogs. Cordes übernahm ein Jahr später die Leitung der UB Saarbrücken, die er bis zu seinem Ausscheiden aus dem aktiven Bibliotheksdienst im Jahre 1970 innehatte. Seit 1963, dem Jahr der Einschaltung in den Leihverkehr, hat der ZKBW circa 7 Mio. Fernleih-Bestellungen bearbeitet. Nach der Makulierung von etwa 3,5 Mio. Titelkarten im Januar 2006, die durch den Nachweis im SWB entbehrlich geworden sind, hat der Zentralkatalog heute noch einen Bestand von circa 8,5 Mio. Katalogzetteln bis 1983 (einschl. Mikrofiche-Nachweise), mit deren Hilfe u.a. die Altbestandsnachweise der Südwest-Region bis 1900 ermittelt werden können. Nicht nur die Nachweise der großen „alten“ Universitäts- und Landesbibliotheken, die zum großen Teil durch die DFG-geförderten Konversionsprojekte in den SWB eingebracht worden sind, sondern auch die der zahlreichen theologischen Spezial-, Adels- und Stadtbibliotheken mit wissenschaftlichem Altbestand sind für die Bibliothekslandschaft Südwestdeutschlands prägend. Vor allem diese Nachweise sind noch nicht im SWB enthalten.

Das dreifache Jubiläum des Bibliotheksservice-Zentrums BadenWürttemberg wurde am 22./23.11.2006 mit einer festlichen Veranstaltung begangen. Im Jahr 2006 ist nicht nur der ZKBW 50 Jahre alt geworden, auch der Südwestdeutsche Bibliotheksverbund (SWB) feierte seinen zwanzigsten Geburtstag, und das Bibliotheksservice-Zentrum Baden-Württemberg (BSZ) wurde vor zehn Jahren gegründet. Die Jubiläums-Veranstaltung, die als 7. BSZ-Kolloquium in den Räumen der Hochschule der Medien in StuttgartVaihingen (Nobelstraße) stattfand und unter der Schirmherrschaft des Ministerpräsidenten des Landes Baden-Württemberg, Günther Oettinger, stand, wurde vom baden-württembergischen Wissenschaftsminister Prof. Dr. Peter Frankenberg mit einem Festvortrag eingeleitet. Darüber hinaus bot das BSZ aktuelle Informationen und Vorträge rund um seine Dienstleistungen und vielfältigen Aktivitäten. 